\title{
Furnaces with vortex burning for burning of wood waste and coal
}

\author{
Evgenii Zhukov ${ }^{1, *}$, Konstantin Menyaev ${ }^{1}$, and Dmitry Taymasov ${ }^{1}$ \\ ${ }^{1}$ Polzunov Altai State Technical University, Barnaul, Russian Federation
}

\begin{abstract}
The paper presents use of wood waste as fuel in industrial thermal power plants. The paper proposes methods of disposal of low calorific fuels produced from waste. The results of physical experiments and numerical simulations showed possible effective application of wood waste as fuel in industrial thermal power plants. The presented boilers are of superior environmental performance as they are equipped with fuel circulation system. The boilers make rational use of wood waste and lower coal consumption in small and medium-sized thermal power plants. New technology is tested in an operating facility.
\end{abstract}

\section{Introduction}

Nowadays, the development industrial power plants requires the significant environmental and economic advantages boilers. The major economic criterion for boiler plants is fuel consumption.

One way to improve the economic efficiency boiler plants - the use of alternative fuels, i.e. wood waste and agricultural waste. Combined burning of low-grade coals and solid biomass fuel would help in addressing the problem of improve the economic efficiency boiler plants. One of the important solid biomass in Siberia is wood waste.

Combined burning of low-grade coal and wood waste in medium power boilers is a very difficult task. The point is that fine particles of wood fuels hard to keep to furnace of boiler. It is quite possible that is formed ash sediment in furnace and convective zone [1]. As a result of this, arise repeated fires in the gas flue of the boiler.

Combined burning of low-grade coal (such as brown coal) and humid wood waste have a number of drawbacks. That prevents from full taking advantage of the energy of a fuel $[2,3]$.

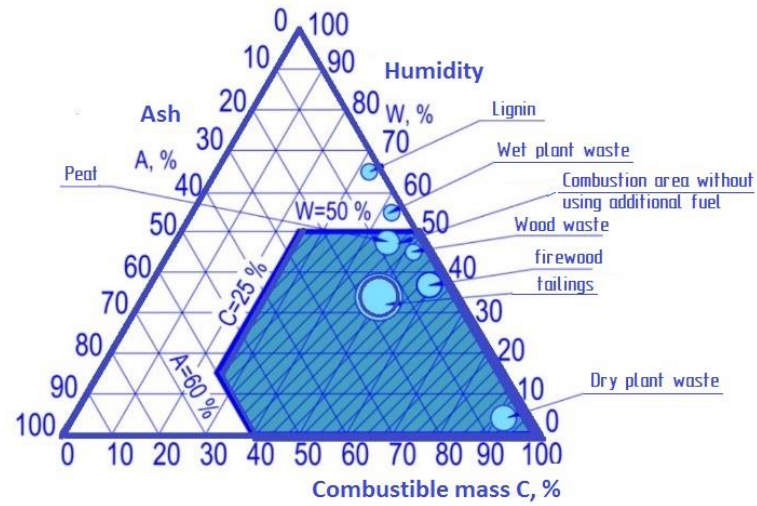

Fig. 1. Tanner's fuel triangle

\section{Methods}

Based on the experience gained, in identifying the limit of the burning was used triangle (Fig.1) [3]. Limit values: combustible material for more than $25 \%$; humidity less than $50 \%$; ash less than $60 \%$. As you can see in the figure 1, autogenous combustion zone is shaded and data of alternative fuels is entered in the triangle field [9]. One can see in a figure 1 that wood waste, peat can be reclaimed of direct combustion, while humid wood waste and lignin shall be prepared to burning (f.e. processed into briquettes). Wood waste is low-ash and high-humid fuel (humidity sometimes reaches $60-70 \%$ ).

Scientists from the Polzunov Altai State Technical University together with "BARNAULENERGOMASH" LTD engineers have explored of alternative fuels characteristics and examined the burning processes. The

\footnotetext{
Corresponding author: jukov23j@yandex.ru
} 
experiments were performed with a view to identifying the fuel dynamic properties in the fuel laboratory of ASTU (Fig.2). These data need for studying the drying, pyrolysis and burning processes.

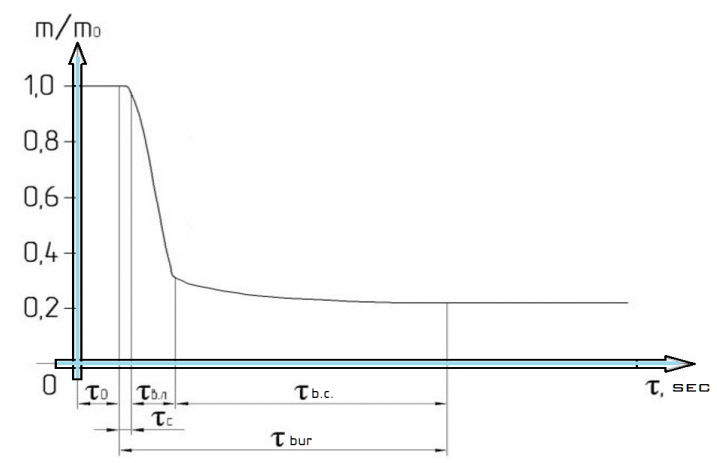

$\tau_{0}$ - time to particle warm-up, $\tau_{\mathrm{c}}-$ time to particle drying, $\tau_{\text {вл. }}-$ time to volatiles release, $\tau_{\Gamma . K .}-$ time to coke particle burning, $\tau_{\Gamma}$

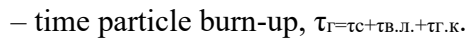

Fig. 2. The dynamic of thermal decomposition of fuel.

During the experiment incinerated particles of wood waste weight from 0,5 to $2,5 \mathrm{~g}$ at a temperature no lower than $500^{\circ} \mathrm{C}$ but no higher than $900^{\circ} \mathrm{C}$. $[1,4]$. During the examination of the thermal decomposition wood waste was plotted the mass loss as a function of time stay in high temperature zone (Fig.2). The dependences of the yield of volatiles on the decomposition temperature are established, the temperature of the maximum yield of volatiles is determined. The yield of volatiles for wood waste in integral (on left) and differential (on right) form shown in the figure 3 .
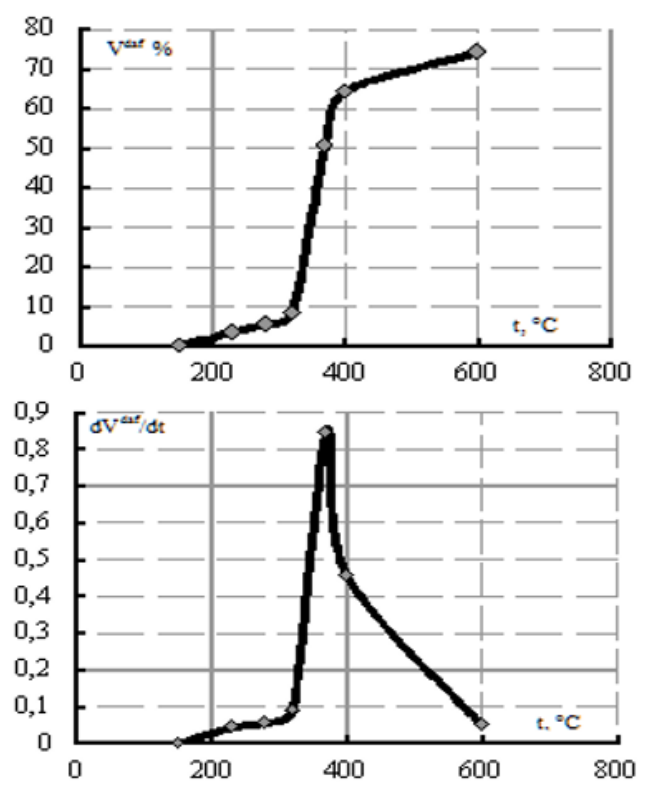

Fig. 3. The yield of volatiles for wood waste in integral (on left) and differential (on right) form.

The combustion process at an early stage differed from process coke burning because of high yield of volatiles. The yield of volatiles and pyrolysis process is a series of parallel and sequential reactions (Fig.3).
Based on the experimental and estimated results designed boilers with multiple fuel circulation in the furnace. (Fig.5). The proposed furnace boiler profile allows to hold low-density particle by the principle of inertial separation (Fig. 4, 5) [6]. The figure 4 are presented 3D model (on left) and pilot plant in the fuel laboratory of ASTU (on right). Inertial separation accepted since gravity separation wood waste is ineffective [7].

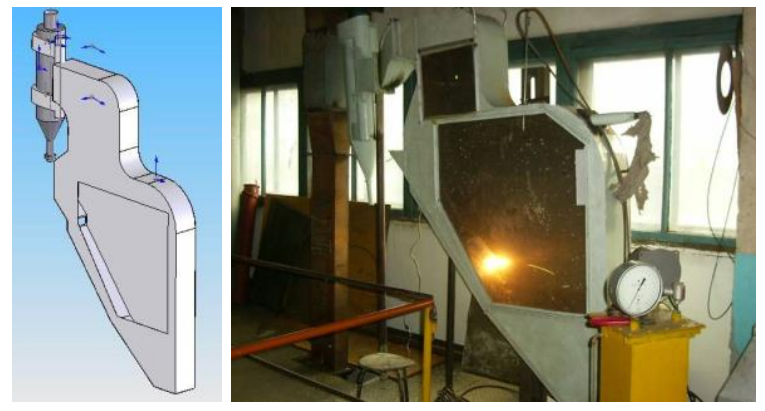

Fig. 4. 3D model of a pilot plant (on left) and pilot plant in the fuel laboratory of ASTU (on right).

Retention of fuel particles in the furnace until they burn deep by means of multiple fuel circulation in the furnace (Fig.5). The aerodynamic configuration was simulated in software complex CFD.

\section{Results and Discussion}

The figure 6 are presented 3D-model boiler "КВм2,5ДВО" for burning wood waste. The figure 7 are presented system a pipeline for boiler with furnace device "ТНФГ", which is designed Scientists from the Polzunov Altai State Technical University together with "BARNAULENERGOMASH" LTD engineers.

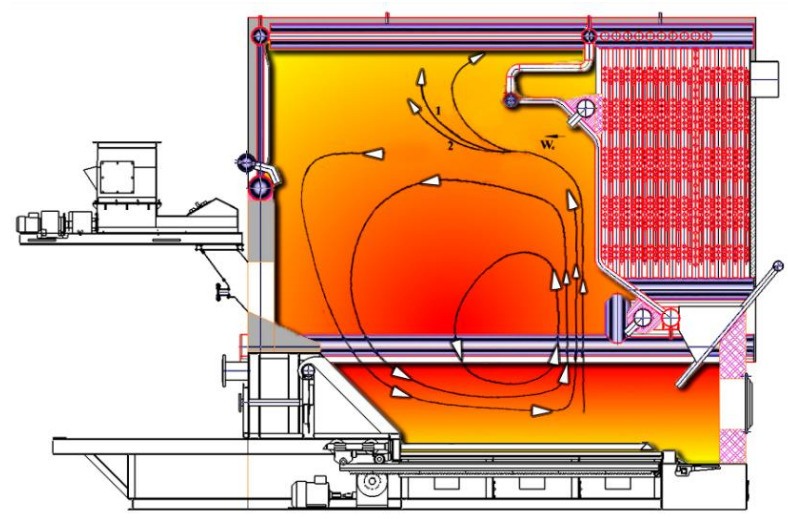

Fig. 5. Aerodynamic situation in the boiler furnace. 


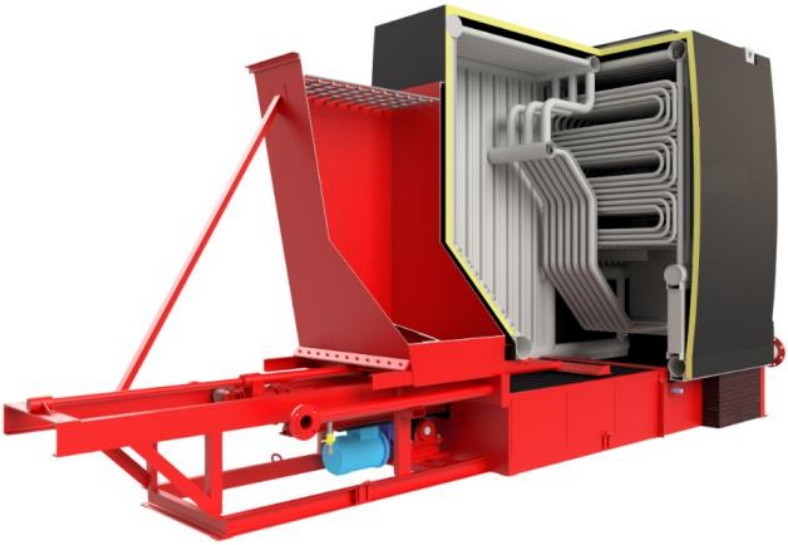

Fig. 6. 3D-model boiler «КВм-2,5ДВО».

The method for combusting wood waste: shredded wood waste served in furnace, where we have the combined flare-layer burning (Fig. 8). Heavy particles run through inclined and horizontal fire-grate, and small particles burn in a whirlwind.

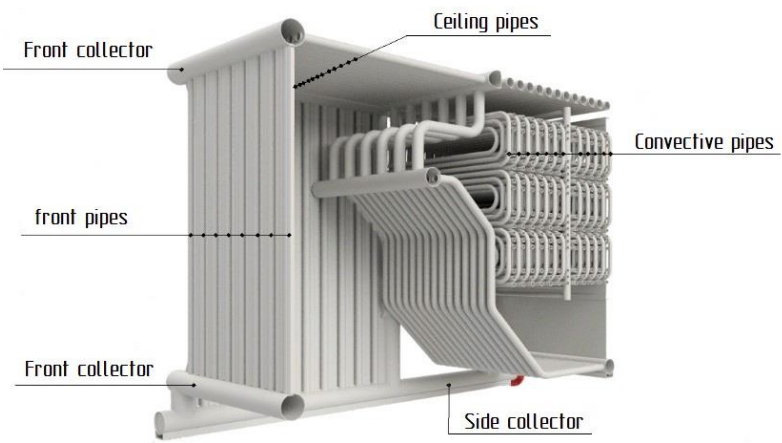

Fig. 7. System a pipeline for boiler.

The system multiple fuel circulation include precipitator of ash, smoke extraction and system nozzles. The boilers with system multiple fuel circulation almost complete burnout occurs fuels.

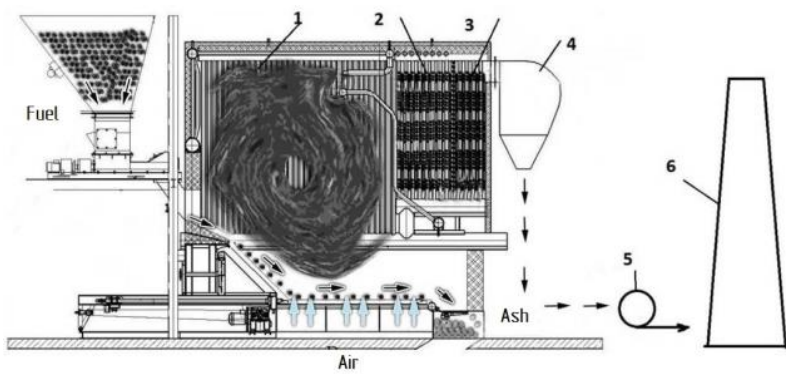

1 - vortex formation in the boiler furnace; 2 - convection pipes (1 stroke); 3 - convection pipes ( 2 stroke); 4 - precipitator of ash; 5 - smoke extraction; 6 - chimney.

Fig. 8. Boiler «КВм-2,5ДВО» for burning wood waste.

The figure 9 are presented 3D-model boiler «E-6,514ИД». This is a steam boiler with a steam capacity of 6.5 tons of steam per hour. The boiler is installed on a furnace-device that allows you to burn wet wood waste.

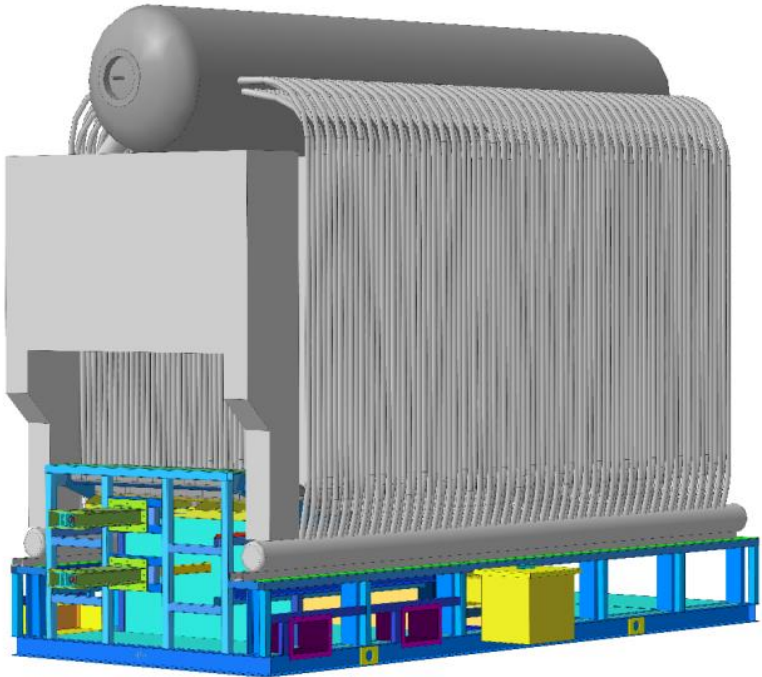

Fig. 9. 3D-model boiler «Е-6,5-14ИД» with furnace-device that allows you to burn wet wood waste.

The boiler furnace is covered with bricks, for burning wood waste with a humidity of more than $50 \%$.

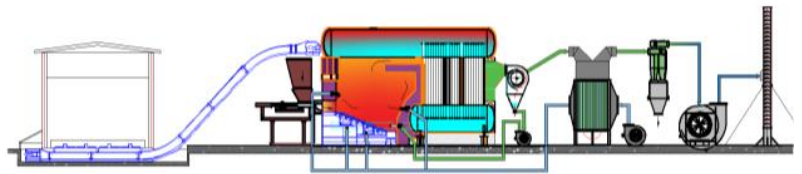

Fig. 10. Boiler plants for burning wood waste with high humidity.

This technology (Fig.10) provides complete combustion of fuel, and consequently increases the efficiency of the steam boiler [13]. Combination of layer combustion (Fig.11) and vortex combustion allows for sustainable burning of wood waste.

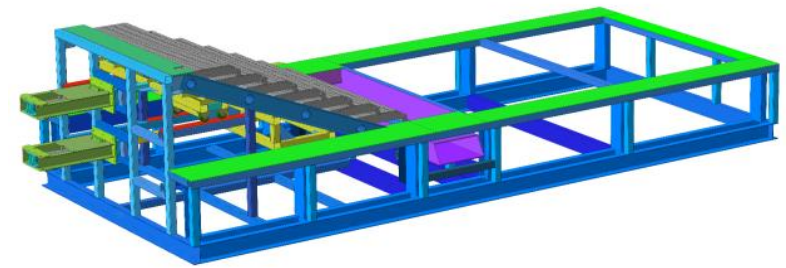

Fig. 11. Furnace-device for burning wood waste with high humidity.

The multiple fuel circulation system has been installed to increase the efficiency of fuel combustion and reduce the amount of unburned fuel. The multiple fuel circulation is carried out through the selection of combustion products from the precipitator of ash. (fig. $10,12)$. 


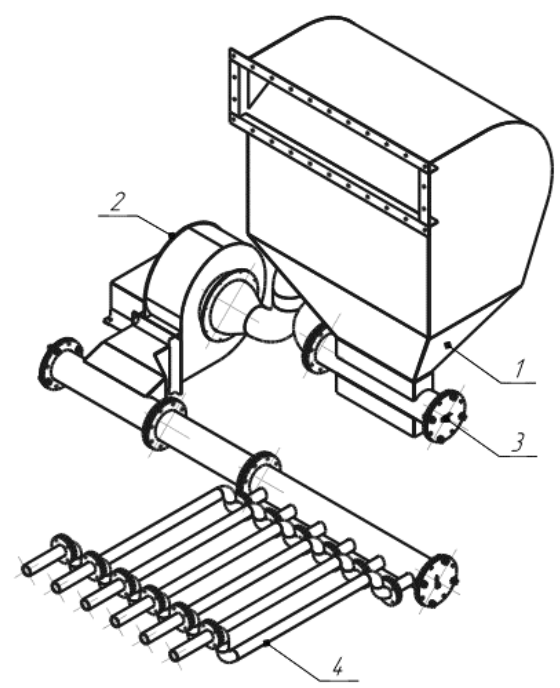

1 - precipitator of ash; 2 - smoke extraction; 3 - An inlet valve; 4 - system nozzles.

Fig. 12. The multiple fuel circulation system.

The multiple fuel circulation system allows you to increase the efficiency of the boiler, reduce fuel consumption and improve the ecology of the boiler (Fig.12)

\section{Conclusions}

The paper presents use of wood waste as fuel in industrial thermal power plants. The paper proposes methods disposal of low calorific fuels, producing from waste. The results of physical experiments and numerical simulations showed that possible effective application of wood waste as fuel in industrial thermal power plants. The presented boilers are of superior environmental performance as it is equipped with fuel circulation system. The boilers make rational use of wood waste and lower coal consumption in small and medium-sized thermal power plants.

\section{References}

1. 1. E.B. Zhukov, I.D. Fursov, I.S. Yakimova, Journal of MODERNSCIENCE: researches, ideas, results, technologies 173 - 178 (2014)

2. 2. E.B. Zhukov, I.D. Fursov, N.S, Gavrin, K.V. Menyaev/ Collection of articles of the I international correspondence scientific-practical conference " problems of technosphere safety-2015" 206-209 (2015)

3. 3. E.B. Zhukov, Puzirev E.M., Menyaev K.V. The 8th International Symposium on Coal Combustion (2015)

4. 4. K.V. Menyaev, E.B. Zhukov, Problems of technosphere safety 2015 I international correspondence scientific and practical conference (2015)

5. 5. E.B. Zhukov, K.V. Menyaev, D.R. Taymasov, Co-combustion technology of coal and wood waste in power boilers. Collection of reports of the III international scientific and practical conference " use of solid fuels for efficient and environmentally friendly production of electricity and heat" (2016)

6. 6. V.V. Pomeranstev, Fundamentals of practical combustion theory: textbook for higher educational institutions 2./.: Saint Petersburg 312 (1986)

7. 7. E.B. Zhukov, I.S. Yakimova, Study of agricultural waste incineration. The journal "Vestnik polzunovskii»/ - Barnaul: publishing house AltSTU (2012)

8. 8. E.M. Puzirev, E.B. Zhukov., V.F.Golubev. Russian patent 86705. Low-temperature vortex furnace Publ (2009)

9. 9. E.B. Zhukov, E.M. Puzirev, I.D. Fursov, E.V. Krasutsky, Investigation of the burning of agricultural waste. Magazine "Polzunovsky Vestnik" 3/1, Polzunov Altai State Technical University, Barnaul: publishing house ASTU 47-50 (2012)

10. 10. T.A. Sitnikova, T.A. Golovina, N.A. Saprykina, Elena P. Tesleva, The Development of Technolo-gy of Basalt Nanocomposite Coatings Detonation-Gas Spaying on the Disk («Target») Basis of Thin Layer Magnetron Spaying Equipment. Materials Science Forum, Trans Tech Publications, 927 (2018)

11. 11. E.B. Zhukov, K.V. Menyaev, Co-combustion technology of coal and wood waste. IV International scientific and technical conference " use of solid fuels for efficient and environmentally friendly production of electricity and heat» collection of reports

12. E.B. Zhukov, K.V. Menyaev, D.R. Taymasov, Reconstruction of BKZ steam boiler-75-39-440 on burning of bark-wood waste and brown coal BULLETIN of the East Siberian state University of technology and management Scientific and technical journal 2(69), 12- 22

13. E.B. Zhukov, K.V. Menyaev, D.R. Taymasov, Technology of burning of bark-wood waste and coal in industrial heat power engineering. trade journal S.O.K. number Publishing house "Media technologies" 9(213),1867 (2019) 